\title{
RETRACTED ARTICLE: Suspended animation: effects on short-term and long-term positive associative memory in Hypsibius dujardini
}

\author{
Alexandra A. Rosser
}

Received: 14 September 2012/Accepted: 13 May 2013/Published online: 24 May 2013

(c) Springer-Verlag Berlin Heidelberg 2013

An investigation carried out by George Mason University revealed that the author could not produce any original laboratory notebooks or electronic copies of any of the data reported in this article. Hence, the validity of the results could not be verified and the suspicion of data fabrication could not be cleared. Moreover, the manuscript was submitted without knowledge of the author's co-workers. The author has now retracted the article in line with the request of the author's university and in consent with the Editorsin-Chief.

\footnotetext{
A. A. Rosser ( $\square)$

Physiological and Behavioral Neuroscience in Juveniles Lab, Krasnow Institute for Advanced Study, George Mason University, 4400 University Drive, Fairfax, VA 22030, USA

e-mail: srosser@brains.gmu.edu
} 